\title{
The Common Problem and Solution of the Enterprise Staff's Ideological Situation Analysis
}

\author{
Er-yu Cai \\ The School of Humanities, Economics and Law, Northwestern Polytechnical University, Xi'an, Shanxi, China
}

\begin{abstract}
Based on the actual situation of the ideological and political work in enterprises, this paper studies the common problems in analyzing the staff's ideological situation, and specifically puts forward the solution from the six aspects, including the early goal setting, topics selection, investigation methods, medium-term problem observation, research refinement, report writing and post mechanism construction. This paper has important practical and realistic significance in exploring enterprise staff's ideological situation and strengthening the effectiveness of ideological and political work.
\end{abstract} Solution

Index Terms - Staff's ideological situation analysis; Problem;

\section{Introduction}

The analysis of staff's ideological situations is an important fundamental job. By doing an all-round research and deduction of the staff's thought in a period, we could get to know their ideas, feelings, the difficulties and problems they meet in the real life. On this basis, we could put forward prediction measures timely to maximally mobilize positive factors and dissolve the disharmonious factors, and gather strength for the enterprise development.

\section{The common problems in the process of staff's ideological situation analysis}

A. The investigation lacks specific goals

Some enterprises just analyzes the staff's ideological situation conforming to the customs quarterly in accordance with the requirements for the superior. However, they lack clear goals and accurate topics for what to analyze, how to analyze and what problem to solve, directly leading to the low value of the analysis.

\section{B. The early stage investigation is not deep and universal}

When carrying out the survey, some enterprises rarely get the real situation from the first-line production team and staff, only listen to the report of the grass-root level without any objective judgment, whose final report will be empty and severely lack universality, authenticity and credibility.

\section{The report does not meet the requirements}

Some enterprises take the staff's ideological situation analysis report as usual general work report and the daily work summary. All the report focus on what they have learned, what they have done and what success they have made, not to mention a word about the staff's thoughts, expectations and appeals. Some even change the title of the quarterly work summary to their superior departments. The three main factors of the paper, including the point, the arguments and proof, could not be found throughout the paper. It has no significance for decision making.

\section{The problem analysis is not thorough}

When analyzing the problems, some units could not grasp the main universal problems and could not analyze the problems with the guidance of policy and theory. They often talk about the problems generally rather than deeply analyze the real problems and their causes, which makes the final decision go to the opposite side.

\section{E. The measures are hard to carry out}

Because the investigation and study are not real and thorough enough, the phenomenon is often taken as the nature. The reports seldom write about the reasons for the problems, the negative effects and the countermeasures. Even the countermeasures have been worked out, they are difficult to implement in the practical work for the lack of pertinence and feasibility.

\section{F. Conceal what is unpleasant and crave for greatness and} success

Some units deliberately conceal the staff's ideological problems or some even don't reflect the real situation in order to fawn on the superiors.

\section{The analyzing methods of staff's ideological situation}

The key of staff's ideological analysis is to carry on the extensive investigation at the grass-roots level. Only the investigation is solid and practical, the materials could be comprehensive, specific, accurate and effective. Based on these materials, we could see the essence through the phenomena, seize the inner link and law of various ideological problems, and then put forward the implement measures to dissolve the contradictions and solve the problems. Therefore, the research level directly affects the results of the analysis and the quality of the report. This requires that the investigators must master the investigation skills.

A. Strengthen the consciousness, clarify the investigation aim

Rambling in the survey not only wastes time and energy but also get the investigators lost. Investigators need to apply dialectics to analyze and predict the staff's emotions and thoughts scientifically by standing in the height of age and starting from the overall interests of enterprises, rather than investigate randomly and blindly.

To ensure the clear goal and way of working, the investigators must strengthen the consciousness of three: one is 
the open consciousness. Because the results of the survey is to provide reference basis for the leadership decision-making, the investigators must have an open vision, stand on the height of the leadership, the height of the macro and ascertain the real state of mind. The second one is advanced consciousness. The investigators must be good at thinking on the issues that the leadership does not or rarely involve and provide the facts and problems to the superiors. The third one is value consciousness. The investigators must be good at "digging through two heads", adhere the policy to the real situation and try to find out the solutions.

\section{B. Optimize subject by repeated comparison}

To optimizing the research topics, we should grasp the following five points: one is the superior's focus, mainly refers to the staff's response to the implementation of the party's line, principles and policies and the major decisions of the enterprise. The second is the staff's doubts. It mainly refers to the staff's understanding of current policies. The third is the hot issues that the staff care. It mainly refers to the problems and solutions about the staff's vital interests in the work and life. The fourth one is the difficulty in the work. It mainly refers to difficult problems and its affects. The fifth one is the little-known "cold spots", which are not widely open but really exist.

\section{Take 5-5 methods, Master the first-hand information}

We should take the initiative in the investigation in the different forms: (1) conference, collect the information through survey meetings and forums; (2) field survey, talk with the staff face to face; (3) individual interview, make interview with individuals and know their real thoughts and feelings; (4) general investigation, mainly adopts questionnaire in a certain period; (5) case study, mainly make a special investigation on a particular problem to find out the regularity; (6) sample survey, investigate the typical workers and then make an deduction.

The following methods can be adopted in the survey: (1) listening method, namely the investigators listen to the staff's opinions carefully and gather their true ideas; (2) dialogue method, namely the investigators and the staff have a talk according to the outline; (3) making an appointment, that is, the investigators choose the topic and give the respondents some time to think, and then do the investigation in order to achieve the expected goal. (4) induction method, for those who are not good at talk, we could give examples or analogies to encourage them to talk; (5) chat method, namely the investigators could talk casually with the staff. What the form and method to investigate depends on the needs of work and the specific conditions.

\section{Do the "five comprehensive", strengthen the effectiveness and pertinence \\ Staff's ideological survey is a very hard and complicated} work in which the investigators need to be serious and careful. First, we should seize the mainstream of staff's thoughts and try to avoid overgeneralizations; second, we should contain both the good and the bad in the survey and try to find out the real reasons; third, solicit opinions from the different employees and absorb the different views, especially listen to the views of different workers to their superior, then provide the first-hand materials; the fourth is to fully listen to public opinions on the internet. With the popularity of internet, network BBS, post bar, such as blogs, microblogging have become important platforms to express opinions. Network expression is real, direct, fast and widely spreading, highly participated, but the rationalization and authenticity are up for debate. After the screening of network public opinions on the true, we could get first-hand resources. The fifth is to report problems objectively and comprehensively. The final report must seek truth from facts, including the good points and the severe problems. Aiming at the shortcomings, we should make predictions and take effective measures to ensure the timeliness and pertinence of the ideological and political work.

E. Seek "truth, creativity, conciseness and comprehensiveness"

In the process of the staff's ideological situation investigation, what the investigators collected is often something about the phenomenon, rather than about the nature. This requires the investigators to touch bottom on the basis of the "pursuit of the truth. The investigation should be "real, new, concise, comprehensive". The so-called "real" is to pursue the truth, against being out of thin air, intentional exaggeration or mistakes, etc. "New" is to reflect new characteristics and the new pulse, that is to say, new ideas, new visions and new examples need to be expressed in vivid and accurate language. "Concise" means that the language is short, concise, logical, easy to understand and to the point. "Comprehensive" means that the integrated analysis should be comprehensive. First, it not only reflects the staff's wishes, but also do good to the enterprise's development. The analysis of the staff's state of mind should put forward the cause of this mentality, the consequences and the measures to take. To different problems and objects, different analysis methods should be adopted. The analysis should be multi-angle, multifaceted and reasonable. Meanwhile, the staff's words need to be quoted and in this way, the analysis could be natural, real and effective and trustful.

\section{F. Improve the process, grasp the change tendency of staff's ideological situation}

The ideological investigation is a long-term task. Through careful staff thought condition analysis activities, we could accumulate the analyzing experience, improve the work process, form the scientific standards, promote the quality of the quarterly, semi-annual analyzing activities, and establish long-term mechanism of dynamically grasp the staff's ideological development.

\section{Conclusion}

In the staff's ideological situation investigation and analysis, the difficulty lies in selecting topics, the importance lies in investigations, the significance lies in the analysis, the conciseness relies on the language, and the effect relies on the 
action. As long as we master the skills of investigation and study, we will be able to write high-quality analysis report, grasp the staff's actual state of mind, and then make the ideological and political work to dispose.

\section{References}

[1] Wang huan, The Research on Staff's Ideological Condition Analysis and countermeasure Research under the New Situation, Journal of Intelligence, vol.23, pp.213, 2012

[2] Liu lei, The Understanding of the Dynamic Development Promotes the Enterprise's Stable Development, City Construction Theory Research (Electronic), vol.8, 2013
[3] Zhou Zifu, Strengthen the Research of Staff's Thought, Enterprise Civilization, vol.9, pp.39-40, 2011

[4] Wang tao, Strengthen the Dynamic Research of Staff's Thought and Elevate the Effectiveness of Ideological and Political Work, Journal Of The Party School Of Shengli Oilfileld, vol.23, pp78-80, 2010

[5] Tan Jinjun, The Practice and Research on the Early Warning Management Mechanism Construction of Staff's Ideological Dynamic Analysis in an Enterprise, Charming China, vol.11, pp361, 2011

[6] Wu Shaoli, About the Specific Methods of Employee's Ideological Management in state-owned enterprises, Modern Enterprise Culture, vol.27, pp73, 2013

[7] Li Zhigang, Build up Ideological Analysis Mechanism and Ensure the Enterprise's Harmony and Stabilization, Overseas Travel And Employment, vol.4, pp.81-82, 2011 